\title{
Deterioration of mortar bars immersed in magnesium containing sulfate solutions
}

\author{
Wolfgang Kunther • Barbara Lothenbach • \\ Karen L. Scrivener
}

Received: 13 July 2012 / Accepted: 14 February 2013/Published online: 21 February 2013

(C) RILEM 2013

\begin{abstract}
Mortars prepared with a CEM I and a CEM III/B binder were investigated in different magnesium sulfate solutions. The main deterioration mechanism for the CEM I was expansion, while surface erosion was dominant for CEM III/B. The presence of sodium, potassium and calcium in a magnesium sulfate solution led to less expansion and less surface deterioration for both, CEM I and CEM III/B, than which was observed in solutions containing only sodium or magnesium sulfate. The presence of a mixture of different cations seems to lower both the surface deterioration and the expansion and might explain why sulfate attack damages are not as frequent in the field as in laboratory tests. Sulfate binding before cracking/expansion is similar in the presence of all different solutions investigated, indicating that the speed of sulfate ingress and the amount of bound sulphate depends during the first months mainly on the binder.
\end{abstract}

Keywords Sulfate attack - Magnesium sulfate . Portland cement $\cdot$ Slag blended cement $\cdot$ Brucite . Magnesium-silicate-hydrate

W. Kunther $(\square) \cdot$ B. Lothenbach

Laboratory for Concrete \& Construction Chemistry,

EMPA, Überlandstrasse 129, 8600 Dübendorf,

Switzerland

e-mail: wkunther@googlemail.com

K. L. Scrivener

Laboratory of Construction Materials, EPFL,

1015 Lausanne, Switzerland

\section{Introduction}

Magnesium is a common cation in natural waters and thus often in contact with concrete structures. The attack is labeled as sulfate attack when the magnesium is combined with sulfate ions, such solutions have been extensively investigated in laboratory studies. The combined occurrence of sulfate and magnesium ions is known to be a severe form of sulfate attack as both the sulfate and magnesium ions interact with cement hydrates [1]. Gollop and Taylor [2, 3] reported that the deterioration is more severe at the edges and corners than at the plane surfaces.

The solubility of magnesium sulfate in water is high. However, magnesium hydroxide (brucite) precipitates in high $\mathrm{pH}$ environments due to a very limited solubility of this mineral. The hydroxide ions are supplied by destabilization of cement hydrates like portlandite and C-S-H. The result of this process is decalcification of the binder with precipitation of gypsum as the released calcium reacts with the sulfate ions in solution.

Testing with magnesium sulfate is reported as being more deleterious for blended cements, like slag blended CEM III/B cement with high levels of cement substitution [4, 5]. Slag blended cements have been reported to show surface deterioration rather than expansion compared to CEM I binders [6]. The formation of M-S-H and brucite have been reported for different cements exposed to magnesium sulfate solutions $[5,7,8]$. M-S-H phases are the last stage of 
deterioration after decalcification of the C-S-H phases $[9,10]$.

The formation of a dense composite layer of brucite and gypsum on the surface has been assumed to reduce the ionic transport [11]. Smaller length changes were reported along with a brucite layer for samples exposed to seawater compared to groundwater, it was suggested that the brucite layer could have slowed down the ingress of ions [11]. However, recent work, by the authors, on the influence of bicarbonates on sulfate attack [12] suggests an alternative explanation for the reduction of length changes due to the destabilization of ettringite, which lowers the likelihood of supersaturation with respect to ettringite and hence expansive crystallization pressure.

National standards, such as ASTM C 1012 [13], were developed for plain Portland cement based binders and these typically use sodium sulfate solutions and focus on length changes. The possibility of testing complex sulfate solutions, containing other or combinations of sulfate salts, is suggested in the ASTM standard for special exposure conditions. However, studies of the deterioration of sulfate salts other than magnesium or sodium are uncommon and mixture solutions are only reported to simulate seawater, with the focus on chloride ingress rather than sulfate attack.

The objective of this work is to understand the differences in deterioration for mortars made from a Portland cement and slag blended cement exposed to different sulfate solutions based on sodium and magnesium sulfates.

\section{Materials and methods}

\subsection{Materials}

The CEM I cement was commercial cement from Germany, the CEM III/B was also a commercial cement, from the same clinker containing $70 \%$ slag addition. The main oxide contents and main clinker phases of the cements used, a CEM I and a CEM III/B, are shown in Tables 1 and 2.

The volumes of the cement, sand and water were kept constant for both mortars. The mortars were produced with water to binder ratios of 0.55 (CEM I) and 0.59 (CEM III/B) as the slag cement has a lower bulk density. The sand to cement volume ratio was 3.8. Sand was used according to DIN EN 196, part 1.

The exposure solutions contained $0.35 \mathrm{~mol} / \mathrm{l}$ sulfate of sodium $(50 \mathrm{~g} / \mathrm{l})$; magnesium $(44.8 \mathrm{~g} / \mathrm{l})$. This high sulfate concentration is comparable to standard tests $[13,14]$. Another magnesium sulfate solution was used with $10 \%$ of this concentration $(0.035 \mathrm{~mol} / \mathrm{l})$. The last sulfate solution tested was a mixture of sulfate salts. A mixture of sodium, magnesium, calcium, and potassium (for detailed composition see Table 3) was chosen to test a sulfate solution containing the most common sulfate salts including calcium sulfate with cation ratios which could also be found in natural waters. Some of the calcium sulfate precipitated from the mixture solution; approx. $10 \%$ of the added calcium sulfates were calculated to be dissolved, the rest buffers the solution and might dissolve at later times, as it could occur if gypsum is present in the surrounding soil or rock.

All test solutions were prepared with deionized water using a solution volume to mortar volume ratio of 20. The solutions were changed after every measurement (as detailed below).

\subsection{Length changes}

Length changes were determined on mortar bars $\left(25 \times 25 \times 150 \mathrm{~mm}^{3}\right)$, which were stored in air-tight buckets separated for each cements and each solution. The bars were cut from mortar slabs to remove the surface layer of dense paste and any carbonated surface layer.

Prior to cutting, the specimens were cured for 1 day in a humidity chamber $(100 \%$ relative humidity over dripping water) during setting and the first day of

Table 1 Chemical composition of the cements used (CEM I 32.5 R, CEM III/B 32.5 N HS LH)

\begin{tabular}{lllllllllll}
\hline $\begin{array}{l}\text { Cement } \\
\text { type }\end{array}$ & $\begin{array}{l}\mathrm{SiO}_{2} \\
(\mathrm{~m} \%)\end{array}$ & $\begin{array}{l}\mathrm{Al}_{2} \mathrm{O}_{3} \\
(\mathrm{~m} \%)\end{array}$ & $\begin{array}{l}\mathrm{Fe}_{2} \mathrm{O}_{3} \\
(\mathrm{~m} \%)\end{array}$ & $\begin{array}{l}\mathrm{CaO} \\
(\mathrm{m} \%)\end{array}$ & $\begin{array}{l}\mathrm{MgO} \\
(\mathrm{m} \%)\end{array}$ & $\begin{array}{l}\mathrm{SO}_{3} \\
(\mathrm{~m} \%)\end{array}$ & $\begin{array}{l}\mathrm{K}_{2} \mathrm{O} \\
(\mathrm{m} \%)\end{array}$ & $\begin{array}{l}\mathrm{Na}_{2} \mathrm{O} \\
(\mathrm{m} \%)\end{array}$ & $\begin{array}{l}\mathrm{CO}_{2} \\
(\mathrm{~m} \%)\end{array}$ & $\begin{array}{l}\mathrm{L} . \mathrm{I} . \mathrm{I} . \\
(\mathrm{m} \%)\end{array}$ \\
\hline CEM I & 20.3 & 5.2 & 3.1 & 63.4 & 2.5 & 2.4 & 0.9 & 0.2 & 0.4 & 1.0 \\
CEM III/B & 29.9 & 9.4 & 1.6 & 47.6 & 4.3 & 4.5 & 0.7 & 0.1 & 1.1 & 0.7 \\
Slag & 37 & 12.6 & 0.5 & 40.5 & 5.4 & 2.4 & 0.6 & 0.4 & 0.3 & 0.0 \\
\hline
\end{tabular}


Table 2 The main cement clinker phases according to Rietveld analysis (typical error $\pm 1-2 \%$ )

\begin{tabular}{lcrll}
\hline Cement & Alite & Belite & Aluminate & Ferrite \\
\hline CEM I & 55.7 & 12.1 & 7.5 & 7.4 \\
CEM III/B & 17.7 & 3.1 & 1.4 & 1.2 \\
\hline
\end{tabular}

Table 3 Molar composition of the sulfate solutions tested

\begin{tabular}{lllll}
\hline $\begin{array}{l}\text { Sulfate } \\
\text { salt }\end{array}$ & $\begin{array}{l}\mathrm{Na}_{2} \mathrm{SO}_{4} \\
(\mathrm{~mol} / \mathrm{l})\end{array}$ & $\begin{array}{l}\mathrm{MgSO}_{4} \\
(\mathrm{~mol} / \mathrm{l})\end{array}$ & $\begin{array}{l}\mathrm{Low} \mathrm{MgSO} \\
(\mathrm{mol} / \mathrm{l})\end{array}$ & $\begin{array}{l}\text { Mixture } \\
(\mathrm{mol} / \mathrm{l})\end{array}$ \\
\hline $\mathrm{Na}_{2} \mathrm{SO}_{4}$ & 0.35 & & & 0.132 \\
$\mathrm{MgSO}_{4}$ & & 0.35 & 0.035 & 0.088 \\
$\mathrm{CaSO}_{4}$ & & & & 0.088 \\
$\mathrm{~K}_{2} \mathrm{SO}_{4}$ & & & & 0.044 \\
\hline
\end{tabular}

hardening and for additional 27 days as slabs in saturated lime solution. Gauge alignments were glued to the ends of the cut mortar bars to improve the repeatability of the measurements. Thereafter the mortar bars were stored for $12 \mathrm{~h}$ in a $95 \%$ relative humidity (climate) chamber to harden the two component epoxy adhesive with very high resistance to water and chemicals and little shrinking potential (Araldite 2014-1) before being placed into solution in air tight buckets. The longest exposure time was 910 days during which no changes of the adhesive were observed in very different aqueous solutions.

Specimen lengths were determined in comparison to an invar bar before sulfate exposure and after 7, 14, $28,56,91$ days of exposure and every 91 days after. Lengths were measured on four specimens.

\subsection{EDS measurements and data treatment}

The microstructural changes were studied on epoxy impregnated, polished and carbon coated cross sections of the mortar bars imaged with backscattered electrons in the SEM (Philips XL 30 ESEM FEG with an acceleration voltage of $15 \mathrm{keV}$ ). The changes of the elemental composition within the mortar bars were followed by energy dispersive X-ray spectroscopy (EDS). The EDS measurements were arranged in rectangular grids of $15 \times 20$ points (vertical and horizontal distances points $=14 \mu \mathrm{m}$ ). The placement of the grids was chosen to represent characteristic areas at the depths investigated. Data fluctuation was high due to the heterogeneous microstructure. The EDS measurements were corrected with the ZAF correction. Oxide contents $\left(\mathrm{SO}_{3}, \mathrm{CaO}, \mathrm{SiO}_{2}, \mathrm{Al}_{2} \mathrm{O}_{3}\right.$, $\mathrm{MgO}, \mathrm{Na}_{2} \mathrm{O}, \mathrm{K}_{2} \mathrm{O}, \mathrm{TiO}_{2}, \mathrm{Mn}_{2} \mathrm{O}_{3}$, and $\mathrm{Fe}_{2} \mathrm{O}_{3}$ ) were calculated from the measured elements. Each individual EDS measurement was assigned with a coordinate which allowed the data of the different grids to be combine as profiles expressed as distance from the surface. EDS analysis of epoxy resin in air voids or cracks, aggregates, unreacted slag and clinker particles were removed after data acquisition based on count rate threshold.

Only the maximum oxide values obtained from a group of measurements at a certain depth are displayed, as this allows identifying the zones of different phases much clearer than an average or median profile. The sulfate contents of the different hydrate phases vary significantly within the phase assemblage; highest for gypsum, lowest for phases that contain no sulfate like C-S-H or calcite. An average of all data points considers thus many points which do not contain sulfate which makes it more difficult to determine the depth up to which sulfates have been incorporated in gypsum, ettringite or monosulfate. The same approach is used also for $\mathrm{CaO}$ and $\mathrm{MgO}$. A moving average of 8 values was applied to enhance the clarity of the lines.

\section{Results}

\subsection{CEM I}

Only small length changes were observed during the first 3 months of sulfate exposure (Fig. 1). The subsequent expansion differed significantly for the different sulfate solutions. The fastest expansion was observed for the sodium sulfate solution. The expansions observed for the magnesium sulfate solution were smaller and the expansion of the mixture solution, which contained mainly sodium sulfate plus lower quantities of magnesium, calcium and potassium, was even lower. The samples exposed to the magnesium sulfate solution of lower concentration expanded less than the samples exposed to magnesium sulfate solution of higher concentration, but similar to the samples exposed to the sulfate mixture solution, although the sulfate ion content is ten times higher in the mixture solution. 
In addition to the expansion, deterioration of the edges and corners of the specimens occurred as early as after 4 weeks for exposure to magnesium sulfate solutions $(0.35 \mathrm{~mol} / \mathrm{l})$. At the higher magnesium concentration $(0.35 \mathrm{~mol} / \mathrm{l})$ brucite precipitated as white deposits on the surface of prisms (Fig. 2a). For the lower magnesium concentration $(0.035 \mathrm{~mol} / \mathrm{l}$; Fig. 2b) and the sulfate mixture solution (Fig. 2c) there was much less deposition of brucite. The detailed microstructural investigations focused on the surfaces away from the ends where one-dimensional transport can be expected.

Figure 2 shows the visual appearance of the ends of the mortar bars at 1 year along with micrographs perpendicular to the main surfaces taken at 1 year for the $\mathrm{MgSO}_{4}$ solution; and around 2 years for the low magnesium and sulfate mixture solutions. The samples exposed in sodium sulfate solution are not shown as these have been discussed elsewhere [12]. The micrographs show samples exposed in solution containing magnesium ions form a brucite layer on the surface. Veins of gypsum can be clearly identified in the high $\mathrm{MgSO}_{4}$ and mixture solutions, whereas there are only a few deposits of this phase around aggregate particles in the low $\mathrm{MgSO}_{4}$ case. There is much more cracking evident in the sample exposed to the high



Fig. 1 Length changes of CEM I mortar bars exposed to different sulfate solutions

magnesium sulfate solution than the other two test solutions.

The sulfate profiles are very similar for the three magnesium containing solutions (Fig. 3) after 91 days of exposure (before larger expansions are observed). It has been shown [15] that the binding before cracking is very similar for sulfate solutions containing different cations $\left(\mathrm{Na}_{2} \mathrm{SO}_{4}, \mathrm{~K}_{2} \mathrm{SO}_{4}, \mathrm{MgSO}_{4}\right.$ and the sulfate mixture; all with $0.35 \mathrm{~mol} / \mathrm{l}$ sulfates) as it is determined by the phase assemblage of the mortar before exposure (amount of AFm phases which can transform to ettringite). Even at a ten times lower sulfate ion
(A)

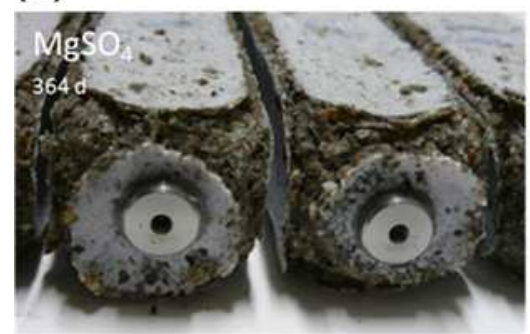

(D)

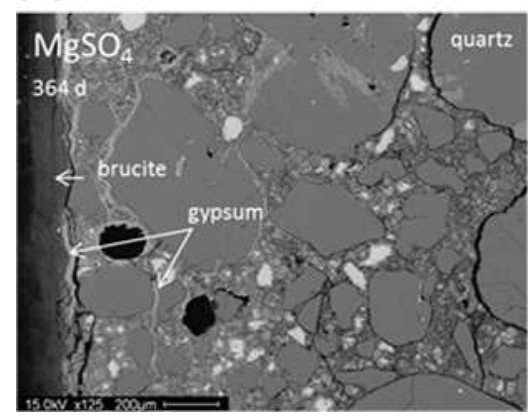

(B)

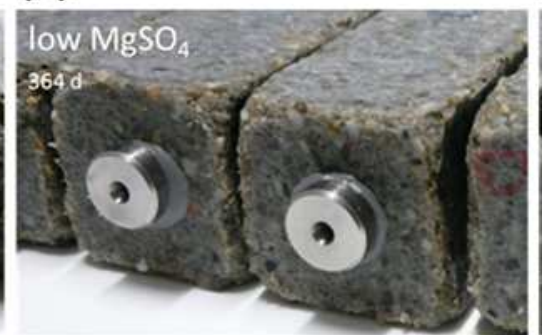

(E)

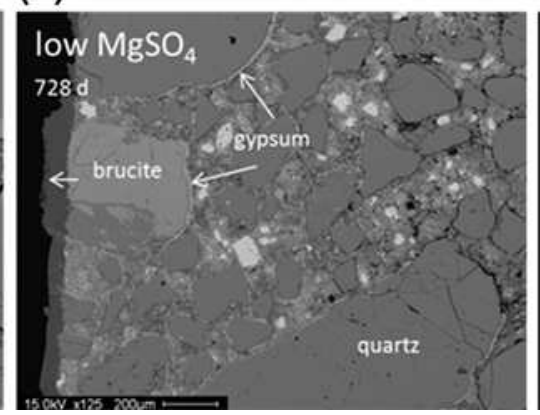

(C)



(F)

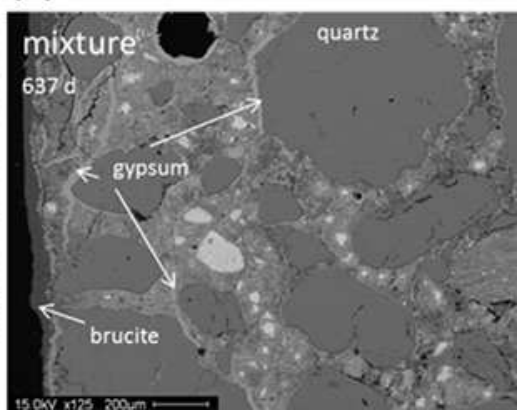

Fig. 2 Visual appearance after 1 year of exposure and later. BSE micrographs of CEM I mortar bars exposed to $\mathbf{a}, \mathbf{d} \mathrm{MgSO}_{4}, \mathbf{b}, \mathbf{e}$ low $\mathrm{MgSO}_{4}$, c, f sulfate mixture solution $\left(\mathrm{Na}_{2} \mathrm{SO}_{4}, \mathrm{~K}_{2} \mathrm{SO}_{4}, \mathrm{MgSO}_{4}, \mathrm{CaSO}_{4}\right.$; see Table 3 for details) 


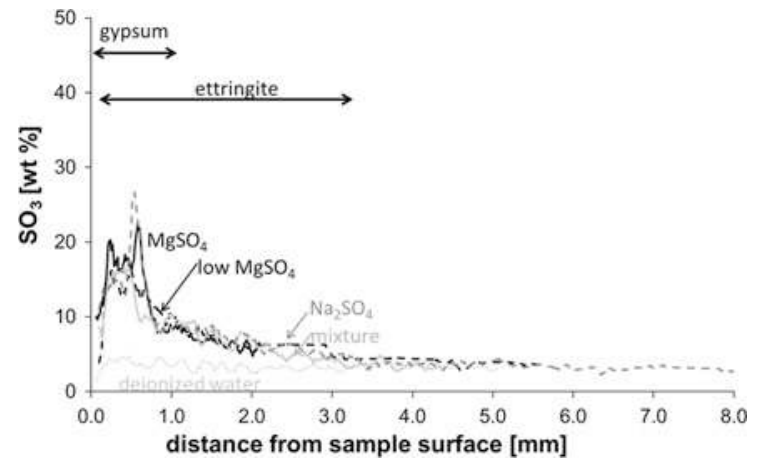

Fig. 3 Median sulfate content profiles of CEM I mortar bars after 91 days exposure to the different test solutions

concentration "low $\mathrm{MgSO}_{4}$ " a similar sulfate uptake in the cement paste is observed after 3 months (Fig. 3, black dashed line). This confirms that during the first months, the speed of sulfate ion ingress and the amount of sulfate binding depends on the binder only.

Figure 4 shows maximum oxide profiles for magnesium, sulfate and calcium, which are more sensitive indicators for phase changes than average profiles. The profiles illustrate that magnesium reacts very rapidly on the surface of the specimens, where brucite precipitates, and the depth of penetration changes little with time (Fig. 4a). Nevertheless, the zone inside of the brucite layer continues to change with the formation of ettringite and gypsum (Fig. 4b) and disappearance of portlandite (Fig. 4b, c). After 1 year, ettringite has formed to a depth of $6 \mathrm{~mm}$, but this sample has cracked by this stage facilitating sulfate ingress.

\subsection{CEM III/B}

The observed length changes of the CEM III/B mortar bars (Fig. 5) are much smaller than for the previously discussed CEM I mortars. Only the exposure to magnesium sulfate solution $(0.35 \mathrm{~mol} / \mathrm{l})$ leads to some expansion and even here a large part of the observed length changes may be due to the severe degradation seen at the ends in proximity of the glued on gauge alignments. The first signs of surface degradation on edges and corners were seen after only 4 weeks of
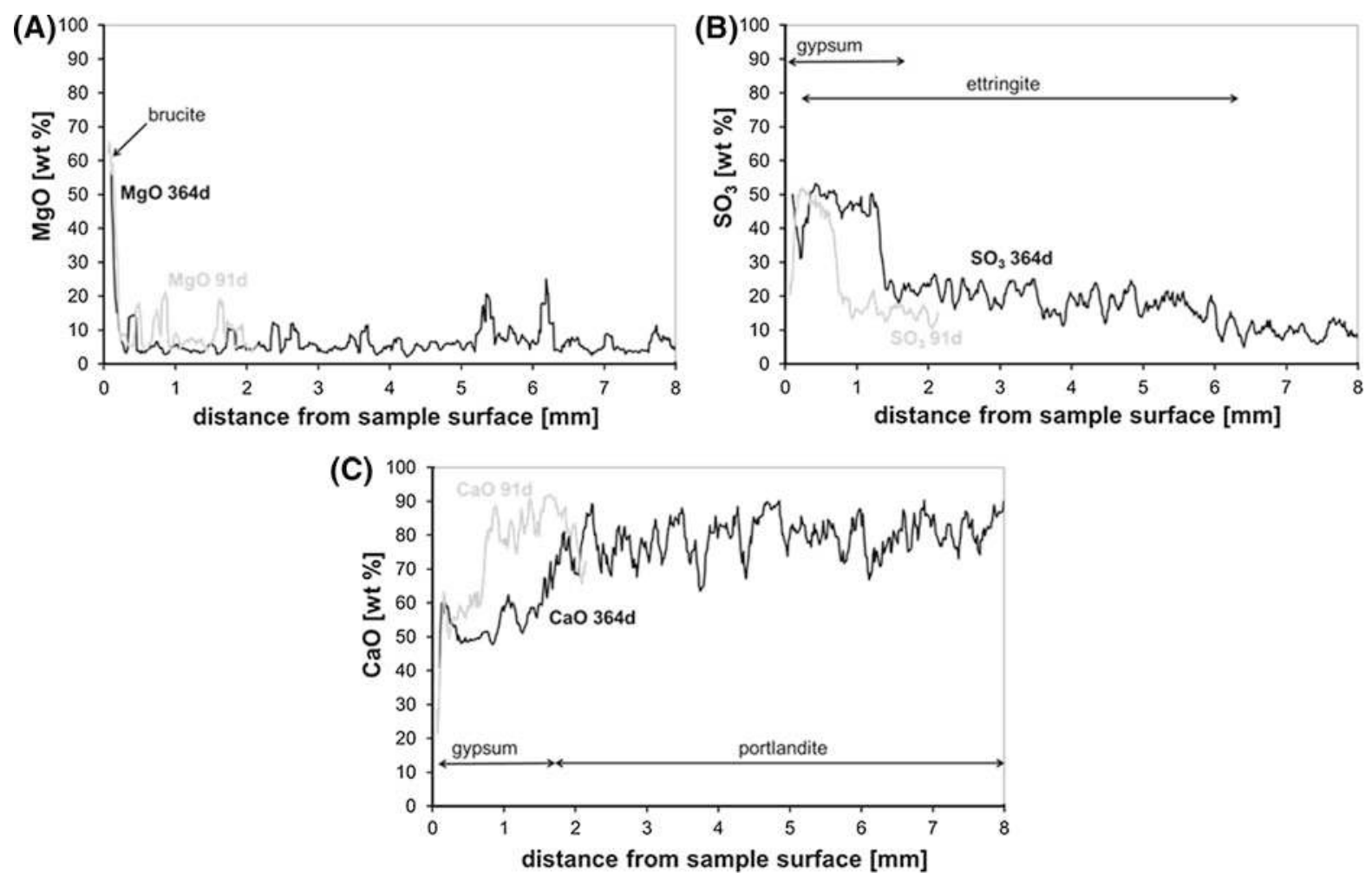

Fig. 4 Maximum oxide content profiles for $\mathbf{a} \mathrm{MgO}, \mathbf{b} \mathrm{SO}_{3}$ and $\mathbf{c} \mathrm{CaO}$ in CEM I mortar bars exposed to magnesium sulfate solution $(0.35 \mathrm{~mol} / \mathrm{l})$ for different times; arrows indicate phases present after 1 year 


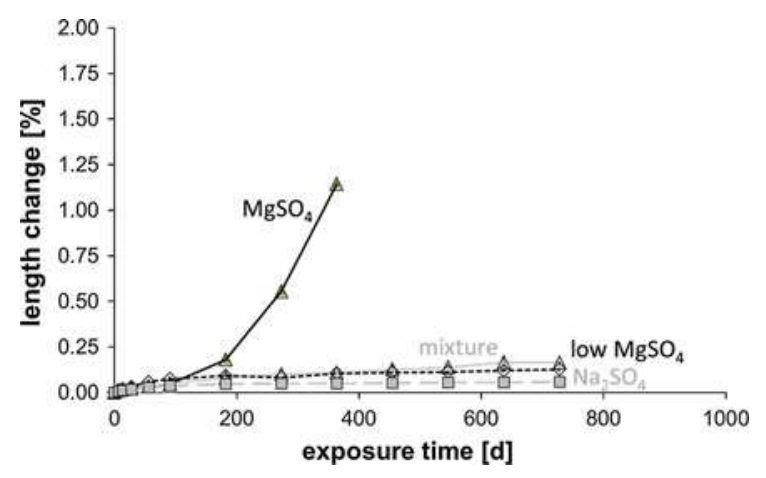

Fig. 5 Length changes and visual appearance of CEM III/B mortar bars exposed to different sulfate solutions

magnesium sulfate exposure; after 1 year the ends were degraded significantly (Fig. 6a). The amount of surface degradation seems visually comparable to that of the CEM I mortars in the same solution, but during handling of the samples the surface of the CEM III samples was clearly weaker and more easily removed.

The samples exposed to the lower concentrated magnesium sulfate solution $(0.035 \mathrm{~mol} / \mathrm{l})$ showed somewhat less spalling at the edges and corners (Fig. 6b), which only progressed slowly during the second year of testing. In this solution the degradation of the surface of the CEM III mortars is clearly more severe than in the CEM I case.

No spalling at edges and corners occurred for the samples exposed to the sulfate mixture solution during the first year (Fig. 6c). This last observation is remarkable as the sulfate concentration is ten times higher and the magnesium concentration 2.5 times higher in the mixture solution compared to the low magnesium sulfate concentration (Fig. 6b). Nevertheless some spalling started on edges and corners for the samples exposed to the sulfate mixture solution during the second year of exposure, which was not the case for the CEM I mortars.

In all three samples gypsum veins have formed and the material between the veins is dominated by M-S-H phase (Fig. 6d-f). The Mg/Si ratios of EDS measurements were mostly between 0.6 and 1 in the M-S-H domains as described in the literature $[2,10]$. The lower calcium content of the slag blended mortars means that gypsum formation leads to a stronger decalcification of C-S-H, so that M-S-H forms instead of leached C-S-H and brucite as in the case of CEM I. As mentioned, the surfaces of the samples in the both pure magnesium sulfate solutions were easily lost during sample handling. So the original surfaces
(A)

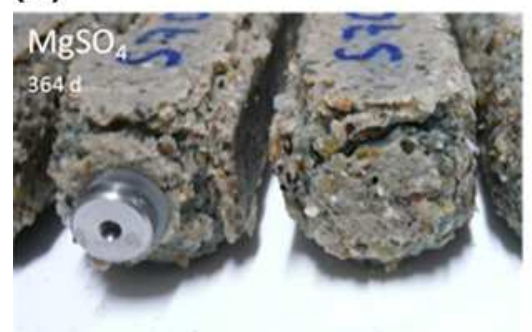

(D)

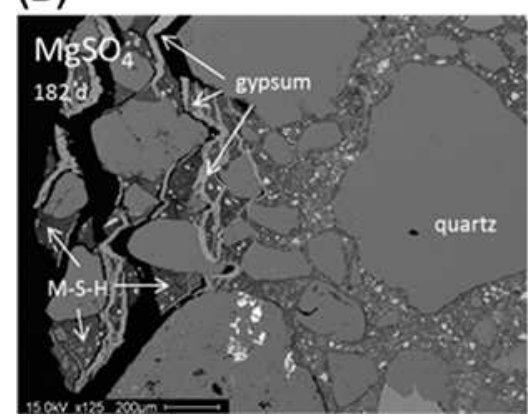

(B)



(E)

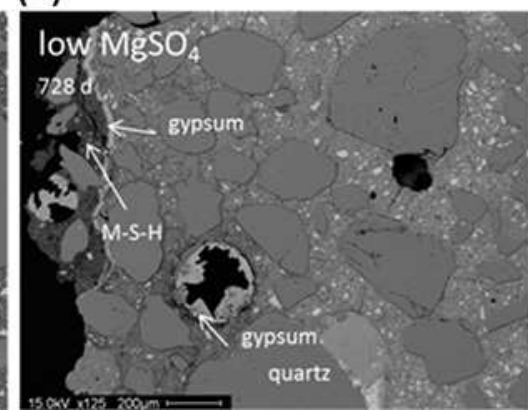

(C)

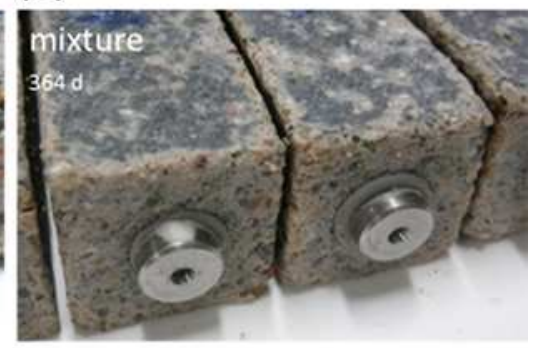

(F)



Fig. 6 Visual appearance after 1 year of exposure and BSE micrographs of CEM III/B mortar bars exposed to a, $\mathbf{d ~ M g S O}$, $\mathbf{b}, \mathbf{e}$ low $\mathrm{MgSO}_{4}$, c, f sulfate mixture solution $\left(\mathrm{Na}_{2} \mathrm{SO}_{4}, \mathrm{~K}_{2} \mathrm{SO}_{4}, \mathrm{MgSO}_{4}, \mathrm{CaSO}_{4}\right.$; see Table 3 for details) 


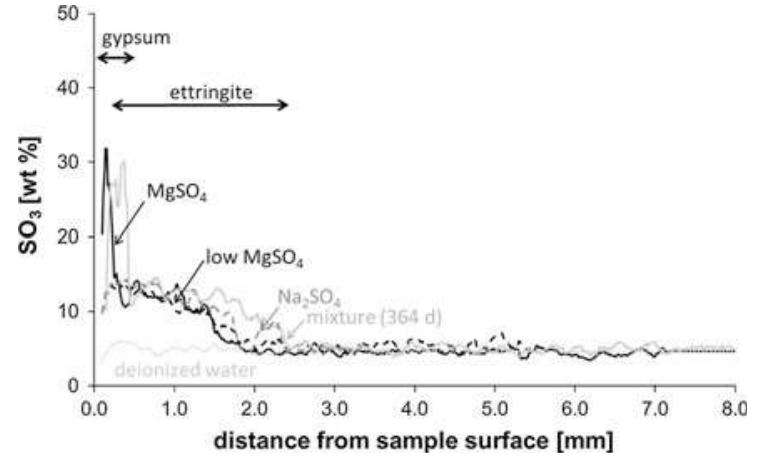

Fig. 7 Median sulfate content profiles of CEM III/B mortar bars after 91 days (and 1 year for the sulfate mixture) exposure to the different test solutions

cannot be identified. Surface erosion for slag blended cements appears to be an iterative process as further phase changes are facilitated by the removal of the previous surface. The irregular surfaces in Fig. 6d, e and particularly the partial lack of an M-S-H region at the surface in Fig. 6e clearly illustrate this phenomenon of surface loss.
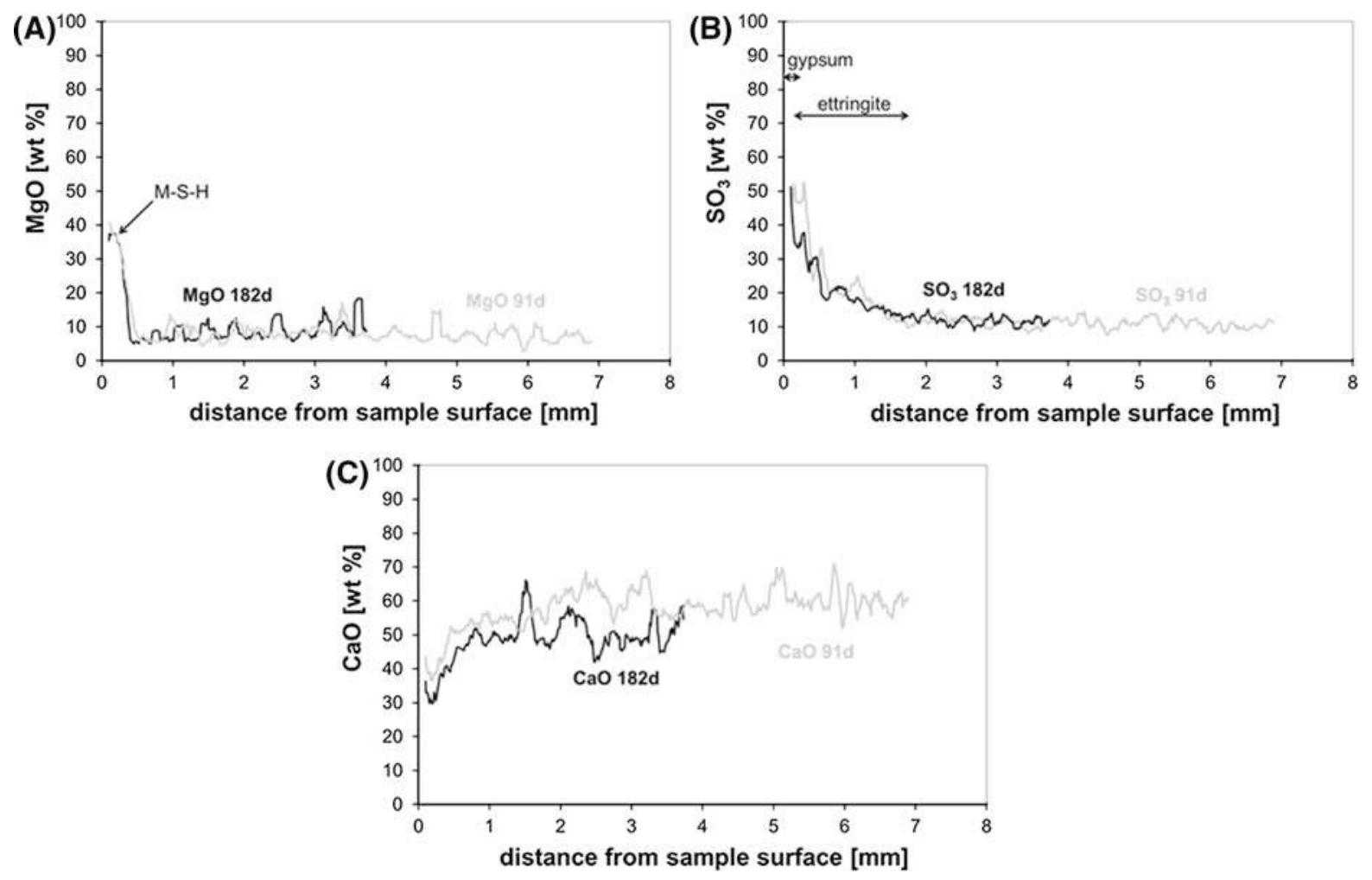

Fig. 8 Maximum oxide content profiles for $\mathbf{a} \mathrm{MgO}, \mathbf{b ~ S O} \mathrm{S}_{3}$ and $\mathbf{c} \mathrm{CaO}$ in CEM III/B mortar bars exposed to magnesium sulfate solution $(0.35 \mathrm{~mol} / \mathrm{l})$ for different times; arrows indicate present phases
Figure 7 shows the sulfate profiles, although there is some uncertainty about the exact depths due to surface loss. Again, the sulfate binding appears to be very similar for the all the mortars with the same binder exposed to the magnesium containing solutions (Fig. 7). However, the sulfate penetration is less than that observed for the CEM I binder. (The profile for the mixture solution is that at 1 year as measurements were not made for this sample at 91 days).

Figure 8 shows the maximum oxide profiles of $\mathrm{MgO}, \mathrm{SO}_{3}$, and $\mathrm{CaO}$. Again, the magnesium penetration is very limited (approx. $<0.6 \mathrm{~mm}$ ). The $\mathrm{MgO}$ content in surface proximity is smaller than for CEM I due to the precipitation of M-S-H instead of brucite.

In contrast to the CEM I mortars, the changes in $\mathrm{SO}_{3}$ and $\mathrm{CaO}$ are also confined to the surface zone (within 1-2 $\mathrm{mm}$ ) and seem to not progress during the test duration, even when expansion of the high $\mathrm{MgSO}_{4}$ sample is observed (Fig. 5). However, as discussed above, the repeated falling off of the surface layers results in the formation of new surfaces which may explain the apparent low penetration depth. 


\section{Discussion}

The CEM I mortar expanded in all the solutions. The expansions seem to "take-off" at similar times, but expand at different rates thereafter. Apart from the low $\mathrm{MgSO}_{4}$ solution, all the solutions have similar concentrations of sulfate ions, so the type of sulfate counter-ion present has an important effect on expansion. In particular the mixture solution which contains both sodium and magnesium ions shows much less expansion than either of the "pure" solutions. The reasons for these differences are not clear, we can speculate that the different ions affect the degree of supersaturation with respect to ettringite in the pore solution, but this cannot be measured directly.

As noted previously a layer of brucite was seen to form on the surface of the CEM I mortars in solutions containing magnesium. However there was no evidence that this prevented the ingress of sulfate ions (as seen in the profiles, Figs. 3, 4) or prevented expansion (Fig. 1). Surface erosion is a less significant form of deterioration for the CEM I mortars as it occurs only on the edges and corners. On the main faces of the prisms the original surfaces persist over long exposure time.

For the CEM III/B binder, surface erosion is the dominant deterioration mechanism. Weak zones, of predominantly M-S-H, form and fall off; exposing fresh surface to degradation. Consequently the sulfate ions do not penetrate to any significant depth and macroscopic expansion does not occur. Any length changes observed are due to surface degradation in proximity of the gauge alignments, and would probably not be seen if the alignment pins were more deeply embedded.

As for the expansion of the CEM I mortars, the surface degradation in the mixture solution was much less for both binders than either of the single salt solutions. And even more remarkably the surface degradation in the mixture solution was much less than the low $\mathrm{MgSO}_{4}$ solution which contained 2.5 times less magnesium and ten times less sulfate. The same general phase changes occur in all three magnesium containing solutions, so it is unclear which factors contribute to the improved performance of the mixture solution, or if these factors differ for the two binders.

\section{Conclusions}

This paper confirms previous observations that the magnesium sulfate solutions cause more surface damage than sodium sulfate solutions. However, the relative importance of expansion and surface deterioration are very different for CEM I and CEM III/B binders. In the CEM I binders expansion dominate deterioration, even when surface deterioration is also present. For the CEM III/B binder, severe surface degradation can occur without any macroscopic expansion being measured. This underlines the unsuitability of expansion related tests for such binders.

The second main conclusion is that samples immersed in solutions containing different cations showed less expansion and also much less surface deterioration than samples containing only $\mathrm{MgSO}_{4}$ or $\mathrm{Na}_{2} \mathrm{SO}_{4}$. The combination of different sulfate salts did not correspond to a superposition of the individual effects. Interestingly, both the surface erosion and the expansion were reduced, although the mechanisms remain unclear at the moment. The fact that a complex sulfate solution leads to slower deterioration process highlights the need to understand the interaction of ions in the test and pore solution better to be able to predict the performance of new binders in general.

Mixed solutions are likely to be present under real exposure situations to natural waters, which might help explain why relatively few cases of sulfate attack are described in the field. In addition, other anions such as bicarbonates (frequently present in natural water) may also strongly reduce the expansion caused by sulfate ions [12].

Acknowledgments Financial support by Cemsuisse is gratefully acknowledged. B. Ingold is thanked for his contribution to the sample preparation and R. Snellings for the Rietveld analyses.

\section{References}

1. Glasser FP (2009) The thermodynamics of attack on cement with special reference to sulfate, concrete in aggressive aqueous environments-performance, testing and modeling. RILEM Publications S.A.R.L, Toulouse, pp 3-17

2. Gollop RS, Taylor HFW (1992) Microstructural and microanalytical studies of sulfate attack. I. Ordinary Portland cement paste. Cem Concr Res 22:1027-1038

3. Gollop RS, Taylor HFW (1995) Microstructural and microanalytical studies of sulfate attack III. Sulfate-resisting 
Portland cement: reactions with sodium and magnesium sulfate solutions. Cem Concr Res 25:1581-1590

4. Lawrence CD (1992) The influence of binder type on sulfate resistance. Cem Concr Res 22:1047-1058

5. Gollop RS, Taylor HFW (1996) Microstructural and microanalytical studies of sulfate attack. IV. Reactions of a slag cement paste with sodium and magnesium sulfate solutions. Cem Concr Res 26:1013-1028

6. Rasheeduzzafar, Al-Amoudi OSB, Abduljanwad SN, Maslehuddin M (1994) Magnesium-sodium sulfate attack in plain and blended cements. J Mater Civ Eng 6:201-222

7. Brew DRM, Glasser FP (2002) Reactions of sulphateresistant Portland cement and its blends with silica fume and aqueous magnesium sulphate. Adv Cem Res 14:101-111

8. Bonen D, Cohen MD (1992) Magnesium sulfate attack on Portland cement paste-I. Microstructural analysis. Cem Concr Res 22:169-180

9. Bonen D (1992) Composition and appearance of magnesium silicate hydrate and its relation to deterioration of cement-based materials. J Am Ceram Soc 75:2904-2906
10. Brew DRM, Glasser FP (2005) Synthesis and characterisation of magnesium silicate hydrate gels. Cem Concr Res 35:85-98

11. Santhanam M, Cohen M, Olek J (2006) Differentiating seawater and groundwater sulfate attack in Portland cement mortars. Cem Concr Res 36:2132-2137

12. Kunther W, Lothenbach B, Scrivener K (2013) Influence of bicarbonate ions on the deterioration of mortar bars under sulfate attack. Cem Concr Res 44:77-86

13. ASTM International (2012) ASTM C1012 / C1012M-12 standard test method for length change of hydraulic-cement mortars exposed to a sulphate solution

14. SIA, SN EN 197-1, SIA 215.002 (2011) Cement part 1: composition, specifications and conformity criteria for common cements

15. Kunther W, Lothenbach B, Scrivener K (2013) On the relevance of volume increase for the length changes of mortar bars in sulfate solutions. Cem Concr Res 46:23-29 